\title{
ANÁLISE DA QUALIDADE DOS SERVIÇOS DE HOSTELS EM OURO PRETO - MINAS GERAIS
}

\section{ANALYSIS OF THE QUALITY OF HOSTELS SERVICES IN OURO PRETO -MINAS GERAIS}

\author{
Denis Akio Macedo Yamauchi ${ }^{1}$ \\ Bárbara Cristina Mendanha Reis ${ }^{2}$ \\ Maurinice Daniela Rodrigues ${ }^{3}$
}

\begin{abstract}
Resumo
Este estudo objetiva analisar as principais características da qualidade de serviços em hostels em Ouro Preto a partir da perspectiva do cliente. Como teorias de base, utilizou-se a qualidade em serviços e a adaptação da escala ServQual para o meio de hospedagem em estudo. Trata-se de uma pesquisa do tipo survey, com questionários aplicados a 98 hóspedes. A pesquisa também utilizou entrevista indepth e análise de websites. Como principais resultados, detectou-se que segurança, localização e preço foram os aspectos mais citados para qualidade esperada, enquanto que, na qualidade experimentada, a qualidade dos funcionários, limpeza e localização foram os aspectos mais destacados. Em relação aos itens que mais geram satisfação, tanto questionários quanto websites apontaram a qualidade dos funcionários, as instalações e a localização. A partir dessa análise, verificou-se imprescindível a capacitação dos funcionários a fim de garantir os resultados já obtidos, assim como melhorias em instalações e segurança, por exemplo, a fim de aproximar qualidade esperada e experimentada.
\end{abstract}

Palavras-chave: qualidade em serviços; hostels; qualidade esperada; qualidade experimentada; ServQual.

${ }^{1}$ Graduado em engenharia de produção pela Universidade Federal de Ouro Preto (UFOP). E-mail: denisakio@outlook.com

${ }^{2}$ Mestre em engenharia pela Universidade Federal de Minas Gerais (UFMG). Atualmente é doutoranda em Engenharia de Produção pela UFMG e professora assistente da Universidade Federal do Mato Grosso do Sul (UFMS) no curso de Engenharia de Produção.E-mail: barbara.reis@ufop.edu.br

${ }^{3}$ Mestre em Engenharia de Produção pela Universidade Federal de Minas Gerais (2012) e doutoranda em Administração de Empresas pela Fundação Getúlio Vargas. Atualmente é professora da Universidade Federal de Ouro Preto, atuando principalmente nos seguintes temas: engenharia do produto e qualidade. E-mail: maurinicerodrigues@yahoo.com.br

Artigo recebido em: 16 de julho de 2018. Artigo aceito em 02 de junho de 2019.

\begin{abstract}
This study aims to analyze the main characteristics of the quality of services in hostels in Ouro Preto from the perspective of the client. As basic theories, we used the quality of services and the adaptation of the ServQual scale for the hosting environment under study. This is a survey-type survey, with questionnaires applied to 98 guests. The research also utilized in-depth interview and analysis of websites. As main results, it was detected that security, location and price were the aspects most cited for expected quality, while in the quality experienced, the quality of the employees, iness and location were the highlights. In to the items that generate the most , both questionnaires and websites location. train the employees in order to guarantee the results already obtained, as well as improvements in facilities and safety, for example, in order to approximate expected and experienced quality.
\end{abstract}

Keywords: quality in services; hostels; expected quality; experimental quality; ServQual. 


\section{Introdução}

A cidade de Ouro Preto em Minas Gerais tem um grande potencial para o lazer e turismo por se tratar de uma cidade histórica reconhecida como patrimônio cultural mundial pela Unesco no ano de 1980 (UNESCO, 2016). Além da arquitetura barroca e colonial, a cidade é palco de diversos eventos, como carnaval, festival de inverno, mostras de cinema, entre outros, durante o ano todo. Logo, os serviços de hospedagem representam uma importante atividade econômica para o município.

Em 2017, Ouro Preto contava com 18 empreendimentos que se autointitulam hostel, conforme pesquisa feita em websites e visitas in loco; sendo assim, surge a necessidade de se oferecer um serviço com qualidade. Em meio a descobrir o que gera a qualidade nesse tipo de serviço e, por consequência, a satisfação do cliente, o objetivo deste trabalho é analisar as principais características da qualidade de serviço em hostels da cidade de Ouro Preto a partir da perspectiva do cliente. Para tanto, o trabalho identifica o perfil do consumidor, as principais características da qualidade dos serviços em hostels e, por fim, mensura a qualidade do serviço em hostels da cidade por meio de uma ferramenta desenvolvida especificamente para esse segmento.

Os hostels oferecem ambientes propícios a uma imersão sociocultural de forma confortável e com preço acessível (HOSTELLLING INTERNATIONAL, 2016). Apesar dos hostels representarem apenas 1,4\% dos tipos de estabelecimentos de hospedagem no Brasil, de acordo com a Pesquisa de Serviços de Hospedagem realizada pelo Instituto Brasileiro de Geografia e Estatística (2017), a percepção e melhoria da qualidade são de extrema importância para os hostels, dado a concorrência de outros meios de hospedagem e as características específicas dessa alternativa. Porém, no Brasil, ainda são raros os trabalhos que abordam a temática, apesar de se tratar de uma área em expansão, no que diz respeito ao setor de hospedagens turísticas (BAHLS; PEREIRA, 2017; THOMAZI; BAPTISTA, 2016). O trabalho justifica-se como uma contribuição a fim de investigar deficiências e fatores relevantes da qualidade segundo a percepção do cliente. Essa análise possibilita a proposição de melhorias desses locais e que, consequentemente, propiciará uma experiência mais satisfatória aos hóspedes.

Os hostels estudados estão localizados em uma cidade mineira, a qual desde a sua fundação recebeu diversificados perfis de viajantes e moradores, principalmente devido ao ciclo do ouro, sendo culturalmente muito plural e tendo características peculiares, 


\section{YAMAUCHI; REIS; RODRIGUES}

como a hospitalidade. A hospitalidade é um atributo reconhecido no brasileiro em geral e nos mineiros em particular (ARRUDA, 1999). A hospitalidade mineira é vista por viajantes estrangeiros como distinta em relação a outras regiões (ABDALA, 2007). Os hostels são um segmento recente, que também possuem características singulares e exclusivas, mais próximas do conceito puro de hospitalidade (BAHLS; PEREIRA, 2017). Nesse sentido, o trabalho também se justifica em relação à localidade do objeto de estudo, culturalmente reconhecido como um ambiente hospitaleiro, por exemplo. As particularidades de Ouro Preto (MG) contribuem para percepções distintas de aspectos da qualidade em hostels em relação àquelas já levantadas em outras localidades, como as do trabalho feito por Gameiro (2013) e de outras futuras pesquisas.

\section{REVISÃO DE LITERATURA}

\subsection{Qualidade em serviços}

Crawford e Benedetto (2016) afirmam que a principal diferença entre bens de consumo e serviços se dá pela característica de intangibilidade dos serviços. Dentre algumas das definições de serviço, Zeithaml, Bitner e Gremler (2014, p. 4) colocam “[...] serviços como ações, processos e atuações oferecidos ou coproduzidos por uma entidade ou pessoa, para outra entidade ou pessoa". Já Juran (1974) define que serviço é o trabalho feito por outra pessoa que oferece para um consumidor, instituição ou ambos.

Segundo Carvalho et al. (2006), os serviços têm características diferenciadoras que os determinam: intangibilidade, heterogeneidade, trabalho não armazenável, necessidade da participação do cliente, simultaneidade e qualidade. Já para Zeithaml, Bitner e Gremler (2014), as características de simultaneidade, intangibilidade e necessidade da participação do cliente são acompanhadas da capacidade perecível com o tempo, escolha do local ditada pelo cliente, intensidade do trabalho e a dificuldade na avaliação dos resultados. Diante dessas características, a qualidade em serviços tem uma abordagem diferente em comparação à qualidade de produto, pois apresenta maneiras distintas em alguns aspectos de percepção de qualidade.

A qualidade em serviços é definida a partir dos clientes que dele utilizam (ZEITHAML; BITNER; GREMLER, 2014). Juran (1974, p. 336) parte do princípio que qualidade em serviços é “adequação ao uso". Para outros autores, como Zeithaml, Bitner e Gremler 
(2014), Fitzsimmons e Fitzsimmons (2014) e Paladini (2006), a qualidade é medida segundo a comparação entre a percepção do serviço prestado e a expectativa do serviço desejado. Para esse julgamento, listam-se cinco dimensões da qualidade em serviços, as quais são: confiabilidade, responsabilidade, segurança, empatia e tangibilidade (FITZSIMMONS; FITZSIMMONS, 2014; ZEITHAML; BITNER; GREMLER, 2014). A percepção dos clientes varia com o tempo, pois existem fatores externos que também influenciam, como cultura, idade, preferências, entre outros (GAMEIRO, 2013). Sendo assim, essa avaliação é bastante difícil devido às características do serviço, pois depende da formação de expectativa acerca do serviço. Nesse sentido, Carvalho et al. (2006) listam quatro fatores que influenciam, a saber: comunicação boca a boca, necessidades especiais, experiência anterior e comunicação externa. Para Zeithaml, Bitner e Gremler (2014), além desses, outros fatores incontroláveis, como o estado psicológico, interferem na formação de expectativa, que se subdivide entre serviço desejado e serviço adequado, sendo o primeiro aquele que o cliente gostaria de receber e o segundo o nível de serviço aceitável pelo cliente. Por isso, a qualidade percebida em serviços é uma componente da satisfação de clientes.

Além dos muitos fatores intangíveis que compõem a qualidade em serviços (FITZSIMMONS; FITZSIMMONS, 2014), a mesma ocorre no processo interativo com o consumidor (PALADINI, 2006), contribuindo assim para uma medição desafiadora. Nesse contexto, o ServQual (Service Quality Gap Analysis) é uma ferramenta que consegue captar as dimensões da qualidade e pesquisar a qualidade do serviço com base no modelo de falha na qualidade em serviços, fundamentando-se na comparação entre o serviço percebido e o esperado (FERNANDES et al., 2017; CARVALHO et al., 2006). O método ServQual é uma concisa escala de múltiplos itens com boa confiabilidade e validade que pode ser usada para melhor entender as expectativas e percepções dos consumidores e, como resultado, melhorar o serviço, podendo ser aplicado nos mais diferentes tipos de serviços (PARASURAMAN; ZEITHAML; BERRY, 1988). O modelo usa de 22 pares de itens com a finalidade de avaliar, por meio de uma média de pontos, cinco dimensões da qualidade: confiabilidade, tangibilidade, responsabilidade, segurança e empatia (PARASURAMAN; ZEITHAML; BERRY, 1988). Essa ferramenta tem uma seção inicial que mede a expectativa dos clientes e uma segunda seção que irá medir a percepção do cliente com relação à empresa de serviço (PARASURAMAN; ZEITHAML; BERRY, 1988). 


\section{YAMAUCHI; REIS; RODRIGUES}

O ramo hoteleiro é um setor de prestação de serviços que segue dimensões da qualidade, como: intangibilidade, ausência de posse e estoque, a ênfase no valor percebido pelo usuário e flexibilidade à dependência do efeito sistêmico de novos serviços; porém existem aspectos de qualidade que são característicos em hotelaria, diferenciando-a de outros serviços prestados, como será descrito a seguir.

\subsection{Qualidade em hotelaria}

A qualidade em hotelaria não se difere de um serviço qualquer, porém possui peculiaridades. Petrocchi (2002) cita cinco dimensões da qualidade total para hotelaria, a saber: intrínseca, custo, atendimento, moral e segurança, sendo que o autor realça que o preço adequado com os serviços e bens oferecidos é um fator marcante no segmento. Silva (2014) reforça que o preço é um fator determinante para a escolha do turista quanto à acomodação, entretanto afirma que com o avanço dos canais de comunicação e a fácil comparação de preços pela internet, outros fatores que relacionam o custobenefício vão determinar a escolha do melhor local.

Os meios de hospedagem não devem se preocupar apenas com a acomodação, mas também com o ambiente como um todo (DIAS; PIMENTA, 2005). Isso implica que os funcionários tenham treinamentos específicos para atender os diferentes tipos de clientes, a fim de satisfazê-los em suas necessidades peculiares.

Branco, Ribeiro e Tinoco (2010) observaram que aspectos como o quarto e o atendimento são atributos da qualidade de mais importância, enquanto os atributos que apresentam maior contribuição para a qualidade percebida são limpeza e conforto do quarto, exatidão das acomodações reservadas, aparência interna e limpeza do hotel. De acordo com os autores, esses atributos são os que irão afetar diretamente nas características da qualidade percebida do serviço, pois são criadas expectativas quanto a elas.

Em outra pesquisa, Nash, Thyne e Davies (2006) analisaram as necessidades específicas do cliente de alojamentos budget (hospedagens com baixo custo, no qual hostels se enquadram) na Escócia. As conclusões encontradas foram que tais turistas buscavam ficar mais tempo nos locais do que turistas de massa e, por isso, a localização e o preço foram os itens mais importantes. A satisfação em relação à qualidade do serviço prestado foi mais influenciada por aspectos de limpeza, custo-benefício e instalação dos 


\section{YAMAUCHI; REIS; RODRIGUES}

hostels.

Hecht e Martin (2006) buscaram entender as características dos hóspedes estrangeiros de hostels da cidade de Toronto. Os autores dividiram a amostra em três grupos, a saber: youth tourists (15-25 anos), transistion back packers (26-29 anos) e contemporary back packers (mais de 30 anos). Os autores verificaram que os primeiros são os que buscam ambientes mais sociáveis e mais propícios a conhecer novas pessoas e culturas, ao contrário dos mais velhos, que estão mais dispostos a pagar mais por privacidade. Nas preferências sobre os serviços foram mais relevantes a limpeza, seguido de localização e qualidade dos funcionários. Por fim, a análise corroborou as percepções de Gameiro (2013) e Lima e Vicente (2016), apontando que as mulheres tendem a preferir hostels mais limpos e seguros, enquanto homens buscam a melhor localização.

Musa e Thirumoorthi (2011), motivados a descobrir as razões pelas quais o Hostel Red Palm, situado na Malásia, foi eleito o melhor hostel do continente da Ásia no ano de 2006, apontaram como as principais dimensões de serviço a localização e limpeza, além da atmosfera acolhedora que o hostel oferecia, fortemente influenciada pela qualidade dos funcionários, uma vez que estes prezavam por um bom relacionamento com os clientes, sendo solícitos, dispondo de atenção individual, além de conhecerem bastante da cultura local.

No trabalho de Gameiro (2013), realizado em hostels na cidade de Lisboa, foram encontrados 18 itens em relação à qualidade do serviço relacionada a quatro dimensões, como: qualidade dos funcionários, atmosfera social, aspectos tangíveis do hostel e conexão com a cidade. Suas principais conclusões destacam o fato de terem $15 \%$ dos hóspedes com mais de 30 anos, algo que não era esperado, além de que $30 \%$ dos clientes já haviam estado em Lisboa antes. Os itens mais bem avaliados pelos hóspedes foram a qualidade dos funcionários e a atmosfera social, já que muitos hóspedes estavam em busca de novas experiências, além de conhecer pessoas. Porém, o fator social perdeu importância com a idade, ou seja, hóspedes mais velhos julgaram itens como segurança mais relevantes. Em relação ao sexo, as mulheres tenderam a dar mais importância para a atmosfera, facilidades oferecidas e segurança.

Em outro trabalho realizado em Lisboa, Lima e Vicente (2016) também buscaram analisar as dimensões da qualidade percebida pelos hóspedes no serviço prestado pelos hostels e os diferentes perfis dos consumidores. Os resultados reforçam os obtidos de Gameiro (2013) em relação à satisfação dos clientes, esta bastante influenciada pelos 


\section{YAMAUCHI; REIS; RODRIGUES}

funcionários dos hostels em questões de competência e zelo. O autor ressalta que apesar do preço ser fator, muitas vezes, determinante para a escolha do hostel, este não é o fator que mais gera satisfação final do cliente, mas ainda assim é um dos itens mais importantes juntamente com a questão de limpeza e higiene. Por fim, em relação aos clientes, os jovens são mais satisfeitos com os serviços prestados e procuram um ambiente com uma boa atmosfera social, e as mulheres mais exigentes quanto à questão de localização e higiene (LIMA; VICENTE, 2016).

Dado que o objeto de estudo deste trabalho são estabelecimentos localizados no território brasileiro no interior de Minas Gerais, faz-se necessário realizar uma breve abordagem em relação à hotelaria, hostels e consumidores no país, o que se dá a seguir.

\subsection{Hotelaria, hostels e consumidores}

O turismo é uma atividade que promove a divulgação e difusão das características socioculturais de um país (IBGE, 2017). Ainda segundo o IBGE (2017), os grandes eventos internacionais realizados no Brasil nos últimos anos fizeram com que o turismo, incluso o setor hoteleiro, investisse em infraestrutura para atender a demanda, o que afetou diretamente nos serviços prestados, qualitativa e quantitativamente, com aumento do ingresso de turistas de 5,4 milhões para 6,6 milhões e receita cambial passando de US\$ 6,1 bilhões em 2011 para US\$ 6,8 bilhões em 2014.

Os serviços de meio de hospedagem encontram-se no último elo da cadeia de serviços turísticos e configuram-se como os mais importantes, já que buscam reproduzir o conforto para uma permanência temporária (IBGE, 2017). Dentre os serviços de hospedagem encontram-se os hostels. A Hostellling International (2016) define-os não apenas como um meio de hospedagem, mas uma acomodação de boa qualidade que oferece uma noite confortável de sono em um ambiente sociável de trocas de culturas por um preço acessível. Segundo a Associação Paulista de Albergues da Juventude (2016), o hostel é um meio de hospedagem econômico, descontraído, ideal para quem gosta de viajar e conhecer novas pessoas e culturas diferentes. Por fim, para o HostelBookers (2016), website especializado em reservas deste tipo de meio de hospedagem, os termos juventude e hostel não estão mais necessariamente interligados, já que $41 \%$ de seus clientes têm mais de 30 anos.

Os hostels no Brasil não são reconhecidos pelo Ministério do Turismo, porém, em 


\section{YAMAUCHI; REIS; RODRIGUES}

pesquisa feita no site do sistema Cadastur do Governo Federal em junho de 2016, é possível encontrar 147 estabelecimentos com o nome fantasia intitulados de hostels cadastrados em operação. Dentro dos associados à Hostelling International Brasil (2016), existem 90 empreendimentos espalhados pelo Brasil. Esses números estão muito longe de expressar a realidade, pois consideram apenas empreendimentos associados ou cadastrados.

\section{PROCEDIMENTOS METODOLÓGICOS}

O presente estudo é uma pesquisa do tipo survey, na qual se fez necessária uma análise histórica e cultural da cidade de Ouro Preto no segmento de hostels, em bases bibliográficas a respeito do turismo nos mesmos, além de uma investigação sobre os hostels presentes no município por meio de websites especializados. Para a medição da qualidade do serviço foi utilizada a escala ServQual, de maneira a analisar seis dimensões da qualidade (atmosfera e ambiente social, localização, preço, limpeza, segurança e instalações) e análise de Gaps, a fim de comparar qualidade esperada e qualidade experimentada.

Duas entrevistas em profundidade foram conduzidas com dois gestores de diferentes hostels em julho de 2016, uma vez que os responsáveis por gerirem os estabelecimentos são os que conhecem melhor seus consumidores, têm a capacidade de estar em contato diariamente com seus hóspedes a fim de trocar informações e analisar os costumes, personalidades, gostos e desgostos (GAMEIRO, 2013). A princípio, os dois gestores escolhidos para as entrevistas eram os representantes dos maiores e mais antigos hostels da cidade; entretanto, dado a recusa do representante do maior hostel, optou-se pela entrevista com o segundo maior hostel (denominado hostel B) e com o gestor do hostel A que possuía peculiaridades frente aos demais, a saber: um número maior de camas por dormitórios e o único que possuía um bar dentro de suas instalações.

Gameiro (2013), em seu trabalho, afirma que, na maioria das vezes, o único contato antes da escolha de reservar um hostel é por meio de websites de reservas online ou sites de indicações de viagem. Esses sites permitem que os usuários avaliem voluntariamente o hostel após a sua hospedagem, de acordo com suas percepções. Portanto, foi feito um estudo dos websites de reservas Hostel World, Trivago, Booking, Hostelbookers e Hostel.com e redes sociais de indicação de acomodações no mês de julho de 2017, a fim 


\section{YAMAUCHI; REIS; RODRIGUES}

de verificar os principais itens avaliados pelos hóspedes.

O público-alvo da pesquisa foram pessoas que já haviam se hospedado em algum hostel na cidade de Ouro Preto, já que essas seriam as pessoas capazes de julgar a qualidade do serviço prestado. A definição do tamanho da amostragem foi feita de acordo com uma determinação probabilística por proporções (MALHOTRA, 2004), seguindo a Equação (1) para a determinação de população infinita, dado ser desconhecido o número de hóspedes.

$$
n=\frac{\sigma^{2} p q}{e^{2}}
$$

Onde:

$\mathrm{n}=$ tamanho da amostra

$\sigma^{2}=$ nível de confiança, expresso em número de desvios-padrão

$\mathrm{p}=$ percentagem com a qual o fenômeno se verifica

$\mathrm{q}=$ percentagem complementar $(100-\mathrm{p})$

$\mathrm{e}^{2}=$ erro máximo permitido

Tendo por base Lima e Vicente (2016), utilizaram-se os valores de erro máximo de $10 \%$ e nível de confiança de $95 \%$, ou seja, $\sigma^{2}=1,96$ para $\alpha=0,05$, obtendo-se assim o número mínimo amostral de 97 questionários respondidos. Por fim, conforme Malhotra (2004), os valores de p e q utilizados foram de 0,5 dado a porcentagem do evento acontecer ser desconhecida.

O questionário utilizado nessa pesquisa foi o desenvolvido pelo trabalho de Brochado e Gameiro (2013), o qual avalia a qualidade do serviço de hospedagem em hostel. Esse questionário teve como base para sua elaboração os modelos do ServQual e o Modelo de Análise de Gaps. Os questionários foram distribuídos em hostels da cidade de Ouro Preto (MG), contando com versões em português e inglês para melhor atender a hóspedes estrangeiros. Os questionários foram aplicados entre julho de 2016 e julho de 2017, sendo que ao final do período obteve-se um total de 103 questionários preenchidos e 98 respondidos completamente, os quais foram considerados válidos. Os dados foram tabulados e analisados no software Statistical Package for the Social 
Sciences (SPSS 22.0).

\section{ANÁLISE E DISCUSSÃO DE RESULTADOS}

\subsection{Entrevista com gestores}

O Hostel A tem três anos de existência e capacidade para 22 hóspedes, enquanto que o Hostel B foi fundado há quatro anos e capacidade para 45 pessoas. Em épocas de eventos, as reservas são mais procuradas, entretanto, durante todo o ano os hostels costumam ficar quase em sua capacidade máxima, devido ao número baixo de leitos nos estabelecimentos. Os entrevistados afirmaram que os motivos que os turistas vão a Ouro Preto são diversos. Varia de cliente para cliente e não há um padrão, porém os mesmos ressaltam que muitos procuram a cidade para o turismo devido a aspectos históricos e atividades ecoturísticas.

A cidade possui uma grande variedade de tipos de acomodações, como hotéis, pousadas, hospedagens, repúblicas estudantis (que recebem turistas para alguns eventos), fazendo com que a competição fique mais acirrada para conseguir e manter clientes o ano todo. Nesse sentido, muitos hostels não conseguem oferecer um serviço diferenciado e de qualidade, culminando na finalização de suas atividades. Entre os anos de 2015 e 2016, cerca de quatro hostels fecharam por não conseguirem se manter durante a crise econômica, fato acarretado, muitas vezes, pelo alto aluguel dos imóveis onde o hostel é instalado.

A segunda parte da entrevista realizou um diagnóstico sobre os hostels. Ambos os entrevistados disseram que cerca de $70 \%$ dos hóspedes fazem suas reservas online e que usam geralmente o website www.booking.com. Em geral, hóspedes brasileiros têm a tendência de fazer suas reservas por telefone, ao contrário dos estrangeiros. A porcentagem de estrangeiros que se hospedam é cerca de $40 \%$ no Hostel A e $25 \%$ no Hostel B. Ainda, foi informado que os brasileiros frequentam mais aos finais de semana, enquanto os estrangeiros durante a semana.

Os dois gestores, quando perguntados sobre o uso dos websites para reservas, foram enfáticos afirmando que estes auxiliam no agendamento, e também são uma das principais formas de divulgação do estabelecimento e meio de avaliação do serviço prestado, uma vez que clientes são capazes de avaliar e deixar comentários positivos e 


\section{YAMAUCHI; REIS; RODRIGUES}

negativos sobre sua estadia. Por fim, os gestores acreditam que os websites são a principal forma de avaliação da qualidade e satisfação dos clientes para os hostels em estudo.

Quando questionados sobre a percepção em relação à qualidade do serviço prestado em hostels, eles afirmaram que os aspectos mais importantes são a relação funcionários e clientes, além da manutenção de boas condições de limpeza e organização nos quartos. Quando compararam os diferentes tipos de clientes, o gestor do Hostel A afirmou que casais são mais exigentes quanto ao serviço prestado. $\mathrm{O}$ mesmo gestor afirmou que outro aspecto importante citado é de que brasileiros ainda têm dificuldade de entender bem o serviço prestado de hostel e esperam um serviço equiparado a de um hotel ou pousada e, por isso, são os que reclamam mais sobre a qualidade percebida. Mulheres procuram locais mais reservados, como quartos com menos pessoas ou mesmo quartos para hóspedes do mesmo sexo.

$\mathrm{Na}$ última parte da entrevista foi questionado o serviço do hostel em si. Ambos os entrevistados responderam que não há um treinamento específico para os funcionários, e que na maioria das vezes os frontliners são os próprios donos, por se tratar de estabelecimentos pequenos. Em relação ao ambiente, os gestores afirmaram que os hostels que são menores têm uma melhor capacidade de promover um ambiente agradável e sociável, entretanto, hostels ouro-pretanos, quando comparados a estabelecimentos europeus, não promovem sessões de boas-vindas, walking tours, pub crawls, mas oferecem, esporadicamente, alguns locais para socialização com música para que os hóspedes possam se juntar e socializar em áreas comuns dos estabelecimentos. Por fim, ambos os gestores afirmaram que a presença de um bar no hostel contribuiria para melhorar a socialização dos hóspedes, porém o mesmo poderia afastar aqueles clientes que não conhecem o estabelecimento e, assim, acreditariam que durante as noites o ambiente ficaria muito barulhento; logo, tal prática não é comum em Ouro Preto.

\subsection{Análise dos websites de reserva}

Em análise do conteúdo de websites de reserva e de redes sociais de indicação de serviços de hospedagem no mês de julho de 2017, os itens avaliados encontrados estão dispostos no Quadro 1. 


\section{YAMAUCHI; REIS; RODRIGUES}

No geral, os aspectos mais bem avaliados são a localização e o serviço/funcionários, corroborando os resultados de Hecht e Martin (2006), que apontam limpeza, localização, serviços, segurança e comodidades como os cinco itens mais avaliados para a escolha de um hostel. Os hostels de Ouro Preto têm uma boa avaliação em média geral dos quesitos avaliados, o que pode ser considerado um fator positivo. A acessibilidade a informações sobre o estabelecimento em mídias de comunicação online é essencial para a escolha do hostel, ao mesmo tempo que obrigam os estabelecimentos a manter um serviço de qualidade, já que serão avaliados posteriormente (SILVA, 2014).

Quadro 1 - Itens da qualidade de serviços prestados em hostels avaliados em websites de reserva e redes sociais de indicação de meios de hospedagem

\begin{tabular}{|c|c|c|c|c|c|c|}
\hline & Website & Hostel World & Trivago & Booking & Hostelbookers & Hostel.com \\
\hline \multirow{10}{*}{ 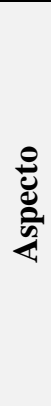 } & Localização & $\mathrm{x}$ & $\mathrm{x}$ & $\mathrm{x}$ & $\mathrm{x}$ & $\mathrm{x}$ \\
\hline & Serviço/Funcionários & $\mathrm{x}$ & $\mathrm{x}$ & $\mathrm{x}$ & $\mathrm{x}$ & $\mathrm{x}$ \\
\hline & Limpeza & $\mathrm{x}$ & $\mathrm{x}$ & $\mathrm{x}$ & $\mathrm{x}$ & $\mathrm{x}$ \\
\hline & Conforto & & $\mathrm{x}$ & $\mathrm{x}$ & & \\
\hline & Wifi gratuito & & & $\mathrm{x}$ & & \\
\hline & Café da manhã & & & $\mathrm{x}$ & & \\
\hline & Comodidades & $\mathrm{x}$ & $\mathrm{x}$ & $\mathrm{x}$ & $\mathrm{x}$ & $\mathrm{x}$ \\
\hline & Custo-benefício & $\mathrm{x}$ & $\mathrm{x}$ & $\mathrm{x}$ & $\mathrm{x}$ & $\mathrm{x}$ \\
\hline & Segurança & $\mathrm{x}$ & & & $\mathrm{x}$ & $\mathrm{x}$ \\
\hline & Atmosfera & $\mathrm{x}$ & & & $\mathrm{x}$ & $\mathrm{x}$ \\
\hline
\end{tabular}

Fonte: dados da pesquisa.

\subsection{Perfil demográfico}

Dentre todos os 98 questionários respondidos, temos uma maioria de homens respondentes, sendo 59,20\% do sexo masculino e 40,80\% do sexo feminino. Quanto ao país de residência, temos uma amostra com uma maioria considerável de hóspedes brasileiros, representando 79,60\%, contra 20,40\% de estrangeiros. Em relação ao estado civil, o público principal $(62,20 \%)$ refere-se aos solteiros; $35,70 \%$ afirmam ser casados ou moram juntos com seus parceiros e apenas 2,0\% são divorciados ou viúvos. Quanto à situação de ocupação, diferente dos resultados de Gameiro (2013), em que a maioria são estudantes, no caso de Ouro Preto, 50\% declararam-se empregados, acrescidos da percentagem de $16,30 \%$ que trabalham e estudam, contra apenas $30,60 \%$ que apenas estudam. O remanescente são os aposentados que representaram $3,10 \%$ da pesquisa.

A faixa etária média foi de 29 anos, com a maioria do público da amostra entre 26 e 29 


\section{YAMAUCHI; REIS; RODRIGUES}

anos (38,78\%), que segundo a classificação de Hecht e Martin (2006) são os chamados transition back packers. Tal resultado, também diferiu dos trabalhos feitos em Lisboa por Gameiro (2013) e Lima e Vicente (2016), nos quais a maioria dos entrevistados eram jovens entre 15 e 25 anos. Os hóspedes acima de 30 anos correspondem a um percentual de 23,46\%, fato esperado, dado que Lima e Vicente (2016) e o website especializado em reservas para hostels ("hostelbookers.com") citam que os clientes de hostels já não são apenas jovens, existindo assim um público heterogêneo.

\subsection{Características de estadia}

Sobre o perfil da visita do hóspede em Ouro Preto, foi possível identificar que aproximadamente um terço dos hóspedes teria visitado Ouro Preto em outra oportunidade, fato este que leva a crer que a cidade proporciona um ambiente favorável ao retorno do turista à cidade. Cerca de três quartos dos turistas já haviam utilizado dos serviços de hostels, sendo que $45,80 \%$ já haviam se hospedado em sete ou mais hostels, ao passo que somente $24,50 \%$ dos respondentes estariam utilizando do serviço pela primeira vez. Cerca de pouco mais de dois terços $(68,40 \%)$ preferem viajar na companhia de outras pessoas, sejam amigos ou membros da família.

Referente ao tipo de transporte utilizado para chegar à cidade, a maioria utilizou de ônibus $(55,10 \%)$, enquanto $41,80 \%$ se deslocaram para a cidade de carro, e apenas $3,10 \%$ utilizaram outro meio de transporte.

Em relação à visita na cidade, 61,20\% afirmaram estar na cidade com o propósito de férias e quanto ao período de estadia, a média de noites variou entre 1 e 11 dias, com média de 4 dias de visita em Ouro Preto. Outros 21,40\% estiveram em Ouro Preto para algum evento que ocorreu na cidade; $11,20 \%$ devido a motivos de trabalho e, por fim, apenas $3,10 \%$ estavam visitando amigos ou família, mesma porcentagem de pessoas que desembarcaram na cidade por outro motivo.

A Figura 1a apresenta dados que indicam que os websites correspondem ao principal meio de conhecimento dos hostels $(63,0 \%)$, seguidos por um percentual de $22 \%$ que afirmaram que, por meio de amigos e familiares, descobriram a existência dos estabelecimentos. Em relação à confirmação das reservas (Figura 1b), $72 \%$ dos hóspedes a fizeram por meio eletrônico, principalmente por websites especializados, fato que corrobora os dados da Figura 1a. Tal divisão reforça o fato apresentado por 
Silva (2014) da importância da comunicação online do empreendimento para atrair o público e fazer negócio em nível global. No mesmo sentido da afirmação anterior, $88 \%$ dos entrevistados (Figura 2b) acreditam ser "extremamente importante" ou "importante" as avaliações realizadas nos websites de reserva, levando em consideração tais avaliações no momento da escolha do local para hospedagem.

\section{Figura 1 - Perfil quanto à reserva: (a) contato inicial e (b) forma de reserva}

(a)

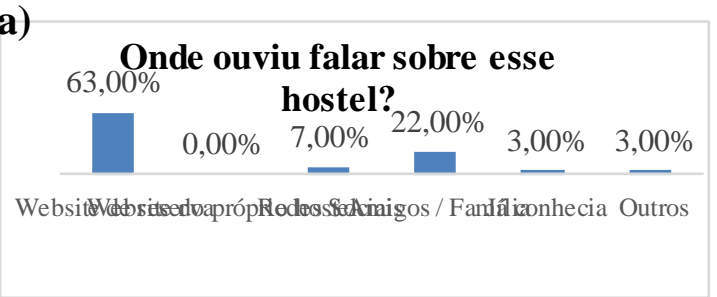

(b)

\section{Como geralmente reserva sua} estadia em um hostel?

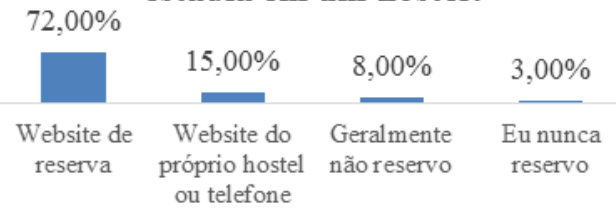

Fonte: dados da pesquisa.

Quanto à confiabilidade dos dados, na Figura 2a, 51\% da amostra acreditam que as avaliações e comentários acerca do estabelecimento estão corretos, enquanto $37 \%$ diz que às vezes estão corretos, mostrando assim que apenas uma pequena parcela desconsidera tais avaliações.

Figura 2 - Perfil quanto a avaliações em websites: (a) percepção e (b) importância

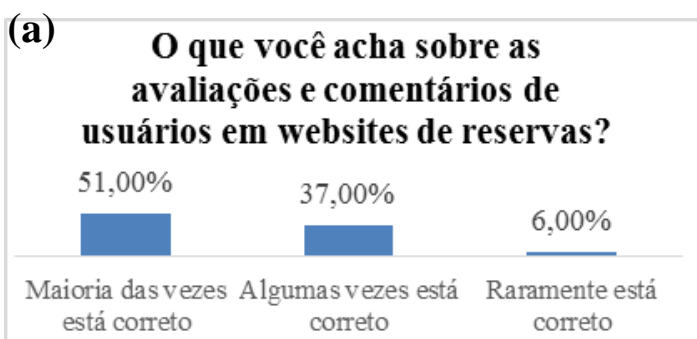

Fonte: dados da pesquisa. (b)

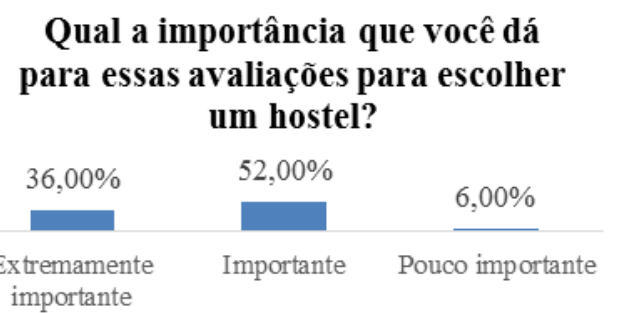

Por fim, conforme ilustra a Figura 3a, 62\% dos hóspedes dizem avaliar e/ou comentar sobre sua estadia no hostel no website em que efetuou a reserva, sendo que dessa porcentagem, cerca de $71 \%$ dizem avaliar independentemente se foi positiva ou negativa a experiência vivenciada, enquanto $20 \%$ dizem avaliar apenas quando algo não agradou e, o restante, no caso contrário, conforme ilustra a Figura $3 b$.

Figura 3 - Perfil quanto à frequência de avaliação: (a) hábito e (b) experiência

(b) 


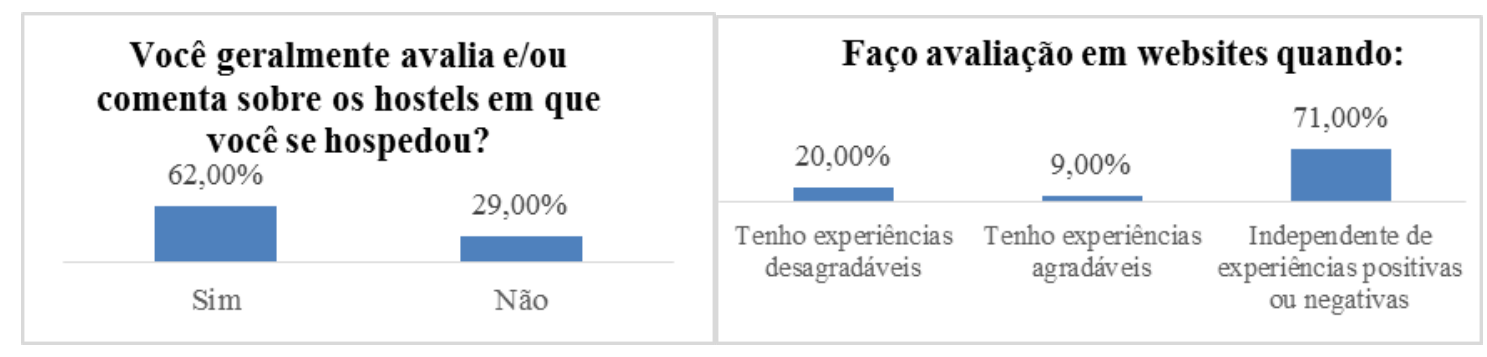

Fonte: dados da pesquisa.

4.5 Itens de qualidade de serviços

Em análise dos resultados sobre a qualidade esperada dos hóspedes de hostels, em termos gerais, a média da expectativa da visita na cidade de Ouro Preto é alta, alcançando um valor de 6,1633 na escala Likert, que varia 1 a 7 , sendo 1 a nota mais baixa e 7 a mais alta. Já em relação à expectativa da estadia no hostel, a média se mostrou um pouco menor com o valor de 5,8878 .

A Figura 4 apresenta a importância média dos itens atmosfera, localização, preço, limpeza e segurança na satisfação do cliente com a estadia em um hostel. Os itens segurança, localização e preço, grifados em verde, foram os considerados mais importantes. De maneira oposta, os menos importantes foram existência de um bar, conhecer pessoas e internet, destacados em vermelho.

Figura 4 - Importância de cada item na satisfação do

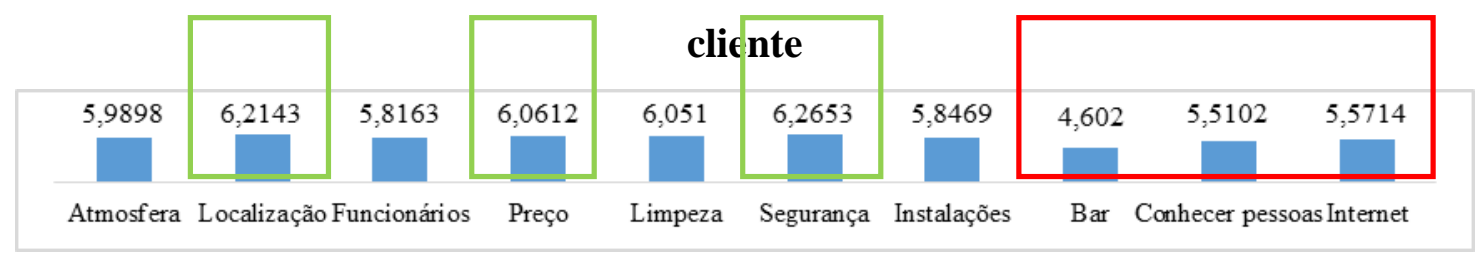

Fonte: dados da pesquisa.

Em análise do questionamento sobre os itens experimentados durante a estadia no hostel em Ouro Preto, a Tabela 1 apresenta as médias segundo a escala Likert de cada item e de acordo com cada dimensão da qualidade.

Tabela 1 - Aspectos das dimensões da qualidade em hostels de Ouro Preto

\begin{tabular}{|c|c|c|c|c|}
\hline Dimensão & \multicolumn{2}{|r|}{ Aspecto } & Média & $\begin{array}{l}\text { Média por } \\
\text { Dimensão }\end{array}$ \\
\hline \multirow{3}{*}{ 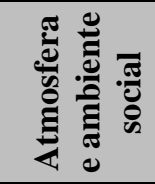 } & 1 & Esse hostel tem o ambiente certo para conhecer novas pessoas & 5,469 & \multirow{3}{*}{5,432} \\
\hline & 2 & Esse hostel promove atividades em grupo & 3,551 & \\
\hline & 3 & $\begin{array}{l}\text { Eu gostei em geral das pessoas que eu conheci aqui durante minha } \\
\text { estadia }\end{array}$ & 5,684 & \\
\hline
\end{tabular}

Revista Eletrônica Gestão e Serviços v.10, n. 1, pp. 2599-2623, Janeiro/Junho 2019.

ISSN Online: 2177-7284 e-mail: regs@metodista.br 


\begin{tabular}{|c|c|c|c|c|}
\hline & 4 & Eu tive diversão nesse hostel & 5,296 & \\
\hline & 5 & O hostel tem um confortável ambiente & 6,316 & \\
\hline & 6 & $\begin{array}{l}\text { A atmosfera do hostel relaciona e encaixa bem com a cidade de } \\
\text { Ouro Preto }\end{array}$ & 6,276 & \\
\hline \multirow{9}{*}{ 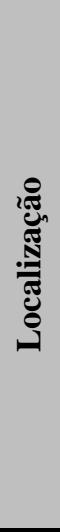 } & 7 & Perto de atrações, bares e restaurantes & 6,235 & \multirow{9}{*}{6,301} \\
\hline & 8 & Perto de meios de transporte & 5,969 & \\
\hline & 9 & Vizinhança segura & 6,245 & \\
\hline & 10 & Perto do centro da cidade & 6,755 & \\
\hline & 12 & Os funcionários conhecem bem Ouro Preto e são prestativos & 6,541 & \\
\hline & 13 & Os funcionários fornecem um serviço eficiente & 6,571 & \\
\hline & 14 & Os funcionários têm uma boa aparência & 6,378 & \\
\hline & 15 & Rápido e correta reserva e check-out feito pelos funcionários & 6,449 & \\
\hline & 16 & $\begin{array}{l}\text { Os funcionários fizeram minha estadia aqui uma melhor } \\
\text { experiência }\end{array}$ & 6,469 & \\
\hline \multirow{2}{*}{ 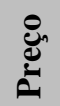 } & 17 & Esse hostel tem bom custo-benefício & 6,520 & \multirow{2}{*}{6,301} \\
\hline & 18 & Eu escolhi esse hostel principalmente por causa do preço & 6,082 & \\
\hline \multirow{4}{*}{ 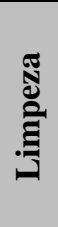 } & 19 & Os quartos são limpos & 6,551 & \multirow{4}{*}{6,4565} \\
\hline & 20 & Os banheiros são limpos & 6,398 & \\
\hline & 21 & A cozinha é limpa & 6,459 & \\
\hline & 22 & A área social / comum é limpa & 6,418 & \\
\hline \multirow{3}{*}{ 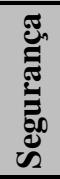 } & 23 & O hostel tem cofres seguros & 5,378 & \multirow{3}{*}{5,8573} \\
\hline & 24 & Existe uma recepção $24 \mathrm{~h}$ & 5,765 & \\
\hline & 25 & Eu me senti seguro nesse hostel & 6,429 & \\
\hline \multirow{10}{*}{ 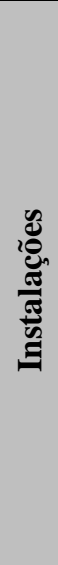 } & 26 & O hostel fornece boa internet e computadores & 4,694 & \multirow{10}{*}{5,2828} \\
\hline & 27 & O hostel tem chuveiros e sanitários privados & 4,694 & \\
\hline & 28 & O hostel possui lavanderia & 3,908 & \\
\hline & 29 & Existe uma ampla área comum & 5,531 & \\
\hline & 30 & Existe um bar & 4,031 & \\
\hline & 31 & A cozinha é bem equipada para cozinhar & 5,531 & \\
\hline & 32 & Existe café da manhã gratuito & 6,592 & \\
\hline & 33 & Não tem muito barulho, é fácil para relaxar e dormir & 5,673 & \\
\hline & 34 & O hostel tem uma atraente decoração & 6,398 & \\
\hline & 35 & O design interior dos quartos é bom & 5,776 & \\
\hline
\end{tabular}

Fonte: dados da pesquisa.

As dimensões que apresentaram notas médias acima de 6, o que é considerado um bom nível de satisfação, foram limpeza $(6,4565)$, localização $(6,301)$ e preço $(6,301)$. Limpeza, pelo fato de os quartos, banheiros, cozinha e área comuns mostrarem-se limpos; localização principalmente pelos hostels da cidade encontrarem-se perto do centro histórico da cidade e próximo das atrações turísticas; e o preço pelo custobenefício.

A dimensão com a nota mais baixa foi a de instalações, com 5,2828. Essa nota mais Revista Eletrônica Gestão e Serviços v.10, n. 1, pp. 2599-2623, Janeiro/Junho 2019. ISSN Online: 2177-7284 e-mail: regs@metodista.br 


\section{YAMAUCHI; REIS; RODRIGUES}

baixa foi influenciada pelas avaliações da não existência de um bar, não possuir banheiros privativos, ausência de boa internet, computadores com baixa capacidade de processamento e, pelo fato, da ausência de lavanderia. Entretanto, nessa mesma dimensão obtiveram-se médias altas para a decoração do hostel e para o café da manhã. Nesse sentido, Fischmann, Andrade e Kim (2014) analisaram os hostels brasileiros e perceberam que tais empresas vêm adotando estratégias de diferenciação em aspectos estruturais, como hostels design, e nos serviços, como quartos e banheiros exclusivos, a fim de atrair mais turistas, comparado com os hostels internacionais.

Outro item com uma nota mais baixa foi o de atmosfera e aspecto social. Principalmente, o item teve uma média puxada para baixo por não promover atividades em grupo, como walking tours, pub crawls, sessão de boas-vindas, que são práticas comuns em hostels europeus. Nesta dimensão, notas medianas foram atribuídas devido ao ambiente ser propício a conhecer pessoas, ser um local agradável e relacionar bem com a cidade de Ouro Preto. Por fim, a dimensão segurança obteve média 5,8573, explicada pelo fato de as pessoas se sentirem seguras no hostel, porém a não existência de cofres totalmente seguros e não existir uma recepção 24 horas, fizeram com que a nota não elevasse.

Diante desses itens avaliados, foi questionado aos hóspedes qual foi o melhor aspecto do hostel em que se hospedaram. Dentre as dimensões apresentadas, o item funcionários foi o mais citado pelos consumidores $(36,7 \%)$, corroborando as notas altas dos aspectos analisados. O segundo item mais citado foi instalações, ou seja, mesmo que o hostel não possua bar, boa internet ou banheiros privativos, isso não influenciou os hóspedes em sua satisfação geral, conduzindo ao fato de que clientes se importam mais com um ambiente agradável e atraente. Fatores como café da manhã gratuito e outros serviços oferecidos são diferenciais na escolha do estabelecimento e não determinantes para a satisfação.

A Figura 5 apresenta os valores de avaliações gerais feitas sobre a estadia em Ouro Preto em um hostel. Os dados mostram que a qualidade percebida do serviço geral do hostel obteve nota média 6,000, o que mostra um bom nível de qualidade experimentada, e a satisfação geral com uma média de 6,347, acreditando-se que a mesma foi atribuída devido ao fator da qualidade dos funcionários, principalmente. Tal resultado corrobora os resultados de Musa e Thirumoorthi (2011), dado que sobretudo o aspecto qualidade dos funcionários fez com que o hostel Red Palm na Malásia fosse 


\section{YAMAUCHI; REIS; RODRIGUES}

considerado o melhor hostel asiático em 2006. Outros fatores, como a limpeza e localização, são citados como importantes na qualidade esperada do hostel (Figura 4), e eles também foram bem avaliados nos itens questionados de qualidade experimentada (Figura 6, 7 e 8). Isso reforça a qualidade dos hostels em Ouro Preto, de acordo com as necessidades e expectativas do turista desse tipo de estabelecimento.

Figura 5 - Média de itens gerais de avaliação da estadia em Ouro Preto

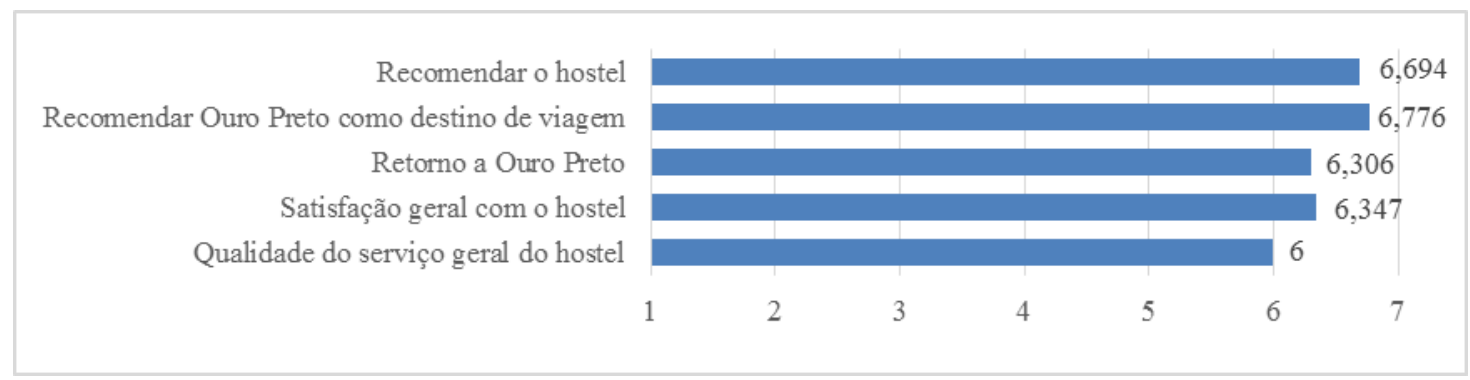

Fonte: dados da pesquisa.

Ainda na Figura 5, verifica-se que outro fato que reforça a qualidade dos hostels de Ouro Preto é a possibilidade de os hóspedes recomendarem o hostel para outra pessoa, dado a atribuição de uma nota bem próxima de 7 (6,694). Como apresentado, as formas das pessoas conhecerem os hostels ouro-pretanos são a recomendação de amigos e familiares bem como as avaliações nos websites de reserva; sendo assim, devido às notas anteriormente mencionadas, a possibilidade dos hostels ouro-pretanos serem recomendados é alta. Nesse sentido, Almeida, Carneiro e Pelissari (2017) afirmam que a qualidade em serviço gera a satisfação e a satisfação do consumidor influencia sua fidelização, representada neste caso pelo seu retorno ao hostel, bem como recomendação do estabelecimento.

Por fim, observa-se na Figura 5 que a possibilidade de os hóspedes retornarem em Ouro Preto também é alta $(6,306)$, corroborando com os dados levantados de que um terço dos entrevistados é de turistas que já estiveram na cidade. Somado a isto, a possibilidade de recomendarem Ouro Preto como destino de viagem também é bastante alta, com uma nota de 6,774, afirmando, mais uma vez, que Ouro Preto é um destino turístico que apresenta atrativos para quem a visita.

4.6 Preferências de serviços

Nessa parte final da análise, tem-se a relação sobre a qualidade dos hostels pelas diferentes perspectivas de cada grupo de idade, país de origem e gênero. Em relação à 


\section{YAMAUCHI; REIS; RODRIGUES}

idade, buscou-se dividir as faixas etárias conforme Hecht e Martin (2006), em que youth corresponde a turistas entre 15-25 anos, transistion aqueles compreendidos entre 26-29 anos e contemporary àqueles com idade igual ou superior a 30 anos. Foram analisados quais os itens que mais influenciam a satisfação durante a estadia em um hostel, e qual foi o aspecto que mais influenciou na satisfação na estadia no hostel em Ouro Preto.

No que diz respeito às preferências de sexo, as principais diferenças são: mulheres esperam e buscam locais mais seguros, com uma boa atmosfera e boa qualidade dos funcionários, ao passo que homens preferem locais com preços mais acessíveis e melhor custo-benefício e, ainda, estão mais predispostos a hostels com uma melhor localização (Figura 6a). No que trata da qualidade experimentada, na estadia em Ouro Preto, Figura $8 \mathrm{~b}$, mulheres e homens citaram a qualidade dos funcionários como o melhor aspecto, $50 \%$ e $27,60 \%$ respectivamente, porém, como qualidade esperada, os homens citaram localização, custo-benefício e preço como sendo o melhor aspecto do hostel, e inesperadamente o item instalações também foi citado por uma parcela dos hóspedes, dado que tal aspecto foi citado na qualidade esperada somente por mulheres.

\section{Figura 6 -Estratificação em relação ao sexo:}

(a) qualidade esperada e (b) qualidade experimentada

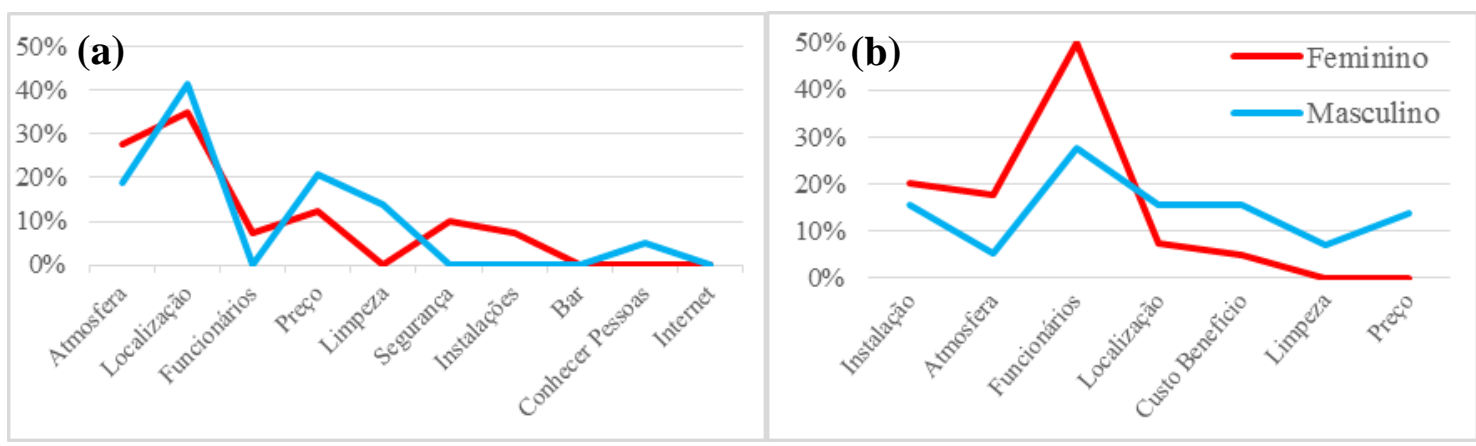

Fonte: dados da pesquisa.

Quanto às diferenças entre os hóspedes brasileiros e estrangeiros, estes últimos esperam hostels com uma melhor localização (60\%), em sua maioria, seguido de preço e limpeza, ambos com porcentagem de $20 \%$ quando questionados sobre o item que mais influencia na satisfação durante a estadia (Figura 9a). Os brasileiros, além da localização $(33,30 \%)$ e preço $(16,70 \%)$, procuram um hostel com uma boa atmosfera $(28,20 \%)$. Quanto à qualidade experimentada (Figura $7 \mathrm{~b})$, ambos citaram como melhor aspecto da satisfação a qualidade dos funcionários, sendo 33,30\% para turista nacional e $50 \%$ para o turista internacional. Outros itens citados pelos estrangeiros foram a localização (15\%), custo-benefício (15\%) e limpeza (20\%), os quais já eram esperados. 


\section{YAMAUCHI; REIS; RODRIGUES}

Ainda em relação aos requisitos mais citados, o brasileiro cita as instalações $(21,80 \%)$ e a atmosfera do hostel $(12,80 \%)$ como importantes para a garantia da satisfação (Figura 7a). Por fim, para esta pesquisa, a principal diferença percebida entre as nacionalidades é que o estrangeiro preocupa-se mais com a limpeza dos locais, importando-se menos com a atmosfera e as instalações dos locais quando comparado aos hóspedes brasileiros.

\section{Figura 7 -Estratificação em relação à nacionalidade:}

\section{(a) qualidade esperada e (b) qualidade experimentada}

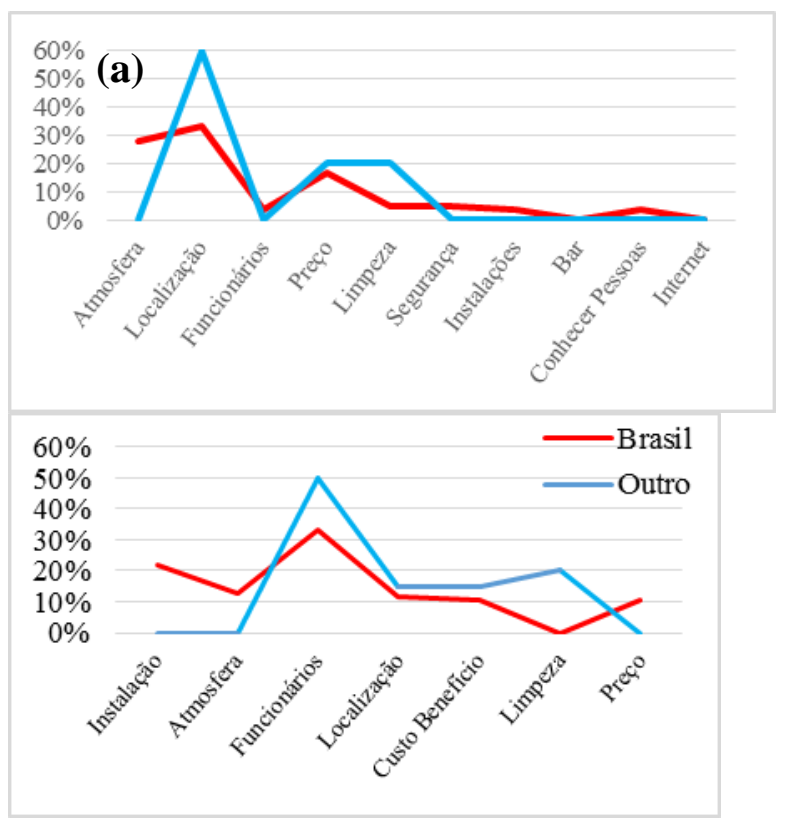

(b)

Fonte: dados da pesquisa.

Por fim, em relação à idade, pode-se perceber as maiores discrepâncias de preferências, conforme ilustram as Figuras $8 \mathrm{a}$ e $8 \mathrm{~b}$. O turista com mais de 30 anos espera um hostel com uma boa atmosfera $(58,30 \%)$, principalmente, e com boa localização $(37,50 \%)$. Enquanto os classificados como transitions buscam um hostel com um bom preço em sua maioria $(43,20 \%)$ e boa atmosfera $(21,60 \%)$ (Figura 8a). Já os mais jovens, entre 15 e 25 anos, em sua grande maioria, esperam um hostel com boa localização $(62,20 \%)$. Outros itens variam entre qualidade dos funcionários, limpeza, segurança e instalações, com porcentagens variando de $8,10 \%$ a $10,80 \%$. Quando questionados qual o melhor aspecto do hostel em Ouro Preto em que se hospedou (Figura 8b), os classificados como youths e transitions citaram a qualidade dos funcionários, em sua maioria, como melhor, com porcentagem de 37,80\% e 43,20\%, respectivamente. Enquanto os mais velhos citaram as instalações em primeiro lugar (37,50\%), seguido de funcionários 
(25\%) e localização (25\%).

Figura 8 - Estratificação em relação à idade:

(a) qualidade esperada e (b) qualidade experimentada

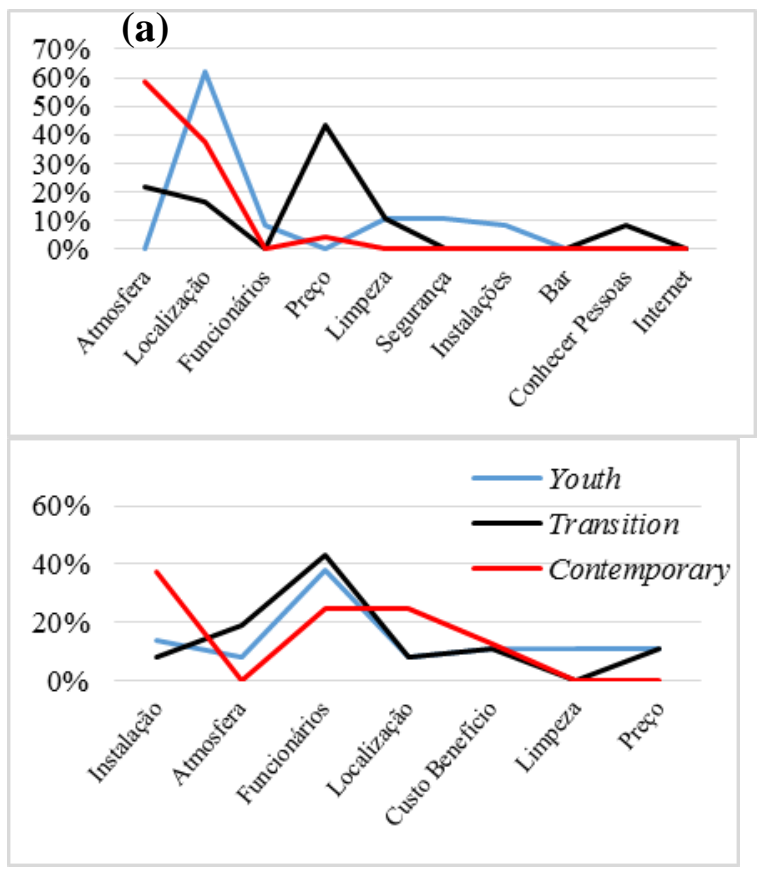

(b)

Fonte: dados da pesquisa.

\section{CONCLUSÕES}

Com relação à qualidade esperada de serviços de hostels de Ouro Preto, as dimensões citadas como mais importantes para a satisfação foram segurança, seguido de localização e preço. Porém, em análise da qualidade experimentada, os principais aspectos citados foram a qualidade dos funcionários, seguido de limpeza e localização. Quando questionados sobre o melhor aspecto do hostel hospedado, os itens mais citados foram: a qualidade dos funcionários, as instalações e a localização, corroborando com os resultados dos websites que apontaram a qualidade dos funcionários e localização como os principais aspectos geradores de satisfação.

Os hóspedes avaliaram a qualidade do serviço com notas altas, e com notas ainda melhores a satisfação da estadia no hostel e a possibilidade de indicar o hostel. Logo, infere-se que a qualidade dos funcionários, em termos de solicitude, educação, bom conhecimento da cidade, atendimento individualizado e bom relacionamento interpessoal com os clientes é o principal fator gerador de satisfação. A localização 
também é um grande influenciador para aumentar a satisfação. Itens como segurança, limpeza e preço foram considerados intrínsecos ao serviço e não geradores de maior satisfação.

A fim de aumentar a satisfação dos clientes, sugere-se que tais estabelecimentos continuem investindo na qualidade de seus funcionários, mas que, também, melhorem itens como segurança e instalações, em termos de decoração e comodidades. Itens de serviço diferenciados seriam fatores agregadores à qualidade, mas não menos importantes do que atividades que promovam um ambiente sociável ou atividades em grupo.

Ressaltam-se limitações da pesquisa dado a dificuldade de obtenção de dados com hostels, uma vez que proprietários de tais estabelecimentos evitavam solicitar aos hóspedes o preenchimento do questionário, já que eles avaliam os mesmos nos websites de reserva, além da extensão do questionário, necessária devido às seis dimensões da qualidade avaliadas, o que fez com que inúmeros hóspedes tornassem indisponíveis para o preenchimento completo. Tais fatores justificam a duração de um ano para a aplicação de questionários.

Para futuros estudos, sugere-se que seja feita uma investigação focada no papel dos funcionários na qualidade do serviço dos hostels, pois foi o aspecto registrado como sendo o que mais afeta o índice de satisfação do cliente. Por fim, ressalta-se que foi feita uma análise descritiva dos dados amostrais, sendo sugerido como trabalhos futuros uma análise exploratória e confirmatória, seja para outras cidades históricas seja para outras regiões brasileiras.

\section{REFERÊNCIAS}

ABDALA, M. C. Receita de mineiridade: a cozinha e a construção da imagem do mineiro. 2. ed. Uberlândia: Edufu, 2007.

ALMEIDA, G. S.; CARNEIRO, T. C. J.; PELISSARI, A. S. Qualidade do serviço e suas consequências: uma análise bibliométrica. Revista Eletrônica Gestão e Serviços, São Bernardo do Campo, n. 8, ano 2, p. 1965-1988, 2017. Disponível em: https://www.metodista.br/revistas/revistas-ims/index.php/REGS/article/view/8045 Acesso em: 10 jul. 2018.

ARRUDA, M. A. do N. Mitologia da mineiridade: o imaginário mineiro na vida política e cultural do Brasil. São Paulo: Brasiliense, 1999. 
ASSOCIAÇÃO PAULISTA DE ALBERGUES PARA JUVENTUDE. O que são hostels? Disponível em:

http://www.alberguesp.com.br/site/conteudo.asp?id_subsecao=2\&amp\%3Btitulo=Conh. Acesso em: 1 mar. 2016.

BAHLS, A. A. D. S. M.; PEREIRA, R. M. F. A. Hostel, uma casa sem paredes: em busca de uma matriz classificatória de áreas físicas. Applied Tourism, Itajaí, v. 2, n. 2 , p. 1-23, 2017. Disponível em:

https://www6.univali.br/seer/index.php/ijth/article/view/11141/pdf. Acesso em: 26 dez. 2018.

BRANCO, G. M.; RIBEIRO, J. L. D.; TINOCO, M. A. C. Determinantes da satisfação e atributos da qualidade em serviços de hotelaria. Produção, São Paulo, v. 20, n. 4, p. 576-588, 2010. Disponível em: http://www.scielo.br/scielo.php?pid=S010365132010000400007\&script=sci_abstract\&tlng=pt. Acesso em: 10 jul. 2018.

BROCHADO, A. O.; GAMEIRO, C. J. S. Developing a new instrument to measure hostels' perceived service quality. III International Congress on Tourism, Tourism Management: Tradition, Innovation and Entrepreneurship, Barcelos, Portugal, 2013. Disponível em: https://ciencia.iscte-iul.pt/publications/developing-a-new-instrument-tomeasure-hostels-perceived-service-quality/12013. Acesso em: 27 dez. 2018.

CARVALHO, M. M. et al. Gestão da qualidade: teoria e casos. Rio de Janeiro: Elsevier, 2006.

CRAWFORD, M.; BENEDETTO, A. Di. Gestão de Novos Produtos. 11. ed. Porto Alegre: AMGH, 2016.

DIAS, R.; PIMENTA, M. A. Gestão de Hotelaria e Turismo. São Paulo: Pearson Prentice Hall, 2005.

FERNANDES, A. M. et al. Qualidade em serviços: percepção discente baseada no modelo SERVQUAL. Revista Eletrônica Gestão e Serviços, São Bernardo do Campo, n. 8, ano 2, p. 2005-2020, 2017. Disponível em:

https://www.metodista.br/revistas/revistas-ims/index.php/REGS/article/view/7755.

Acesso em: 10 jul. 2018.

FISCHMANN, A.; ANDRADE, D.A.C.; KIM, J. Estratégias de inovação no setor de hostels: estudo sobre as realidades brasileira e internacional. VIII Fórum Internacional de Turismo do Iguassu, Foz do Iguaçu, 2014. Disponível em:

http://festivaldeturismodascataratas.com/wp-content/uploads/2014/01/2.-

ESTRAT\%C3\%89GIAS-DE-INOVA\%C3\%87\%C3\%83O-NO-SETOR-DEHOSTELS.pdf. Acesso em: 10 jul. 2018.

FITZSIMMONS, J. A.; FITZSIMMONS, M. J. Administração de serviços: operações, estratégia e tecnologia da informação. 7. ed. Porto Alegre: AMGH, 2014.

GAMEIRO, C. J. S. Service quality in hostels. 2013. 76 f. Tese (Mestrado em Marketing) - ISCT Business School, University Institute of Lisbon, Lisboa, 2013. 
Disponível em: https://repositorio.iscte-

iul.pt/bitstream/10071/6668/1/TESE\%20CARLOS\%20GAMEIRO\%20-

\%20Service\%20Quality\%20in\%20Hostels.pdf. Acesso em: 2 fev. 2017

HECHT, J. A.; MARTIN, D. Backpacking and hostel picking: An analysis from

Canada. International Journal of Contemporary Hospitality Management, v. 18, n. 1, p. 69-77, 2006. Disponível em:

https://www.emeraldinsight.com/doi/pdfplus/10.1108/09596110610641993. Acesso em: 10 jul. 2018.

HOSTELBOOKERS. O que é um hostel? Disponível em:

http://pt.hostelbookers.com/blog/albergues/o-que-e-um-albergue/. Acesso em: 1 mar. 2016.

HOSTELLING INTERNATIONAL. Quem Somos. Disponível em:

https://www.hihostels.com/pt/pages/408/who-we-are. Acesso em: 29 jan. 2016.

HOSTELLING INTERNATIONAL BRASIL. Associações estaduais e FBAJ.

Disponível em: http://www.hihostelbrasil.com.br/associacoes.html. Acesso em: 27 jan. 2016.

INSTITUTO BRASILEIRO DE GEOGRAFIA E ESTATÍSTICA. Pesquisa anual de serviços (PAS): v. 16. Rio de Janeiro: IBGE, 2014.

Coordenação de Serviços e Comércio. Pesquisa de serviços de hospedagem: 2016. Rio de Janeiro: IBGE, 2017.

JURAN, J. M. Quality Control Handbook. 4. ed. Nova Iorque, USA: McGraw-Hill Inc., 1974.

LIMA, R.; VICENTE, P. A qualidade do serviço como determinante da satisfação dos turistas nos hostels de Lisboa: the case of Lisbon. Revista de Gestão dos Países de

Língua Portuguesa, Lisboa, v. 15, n. 3, p. 4-18, set. 2016. Disponível em:

http://www.scielo.mec.pt/scielo.php?script=sci_arttext\&pid=S1645-

$44642016000300002 \& \operatorname{lng}=$ pt\&nrm=iso. Acesso em: 13 set. 2016.

MALHOTRA, N. K. Pesquisa de Mercado: uma orientação aplicada. 6. ed. Porto Alegre: Bookman, 2004.

MUSA, G.; THIRUMOORTHI, T. Red Palm: Red Palm: exploring service quality and servicescape of the best backpacker hostel in Asia. Current Issues in Tourism, v. 14, n. 2, p. 103-120, 2011. Disponível em:

https://www.tandfonline.com/doi/abs/10.1080/13683500903511125. Acesso em: 14 jan. 2017.

NASH, R.; THYNE, M.; DAVIES, S. An investigation into customer satisfaction levels in the budget accommodation sector in Scotland: A case study of backpacker tourists and the Scottish Youth Hostels Association. Tourism Management, v. 27, n. 3, p. 525532, 2006. Disponível em:

Revista Eletrônica Gestão e Serviços v.10, n. 1, pp. 2599-2623, Janeiro/Junho 2019.

ISSN Online: 2177-7284 e-mail: regs@metodista.br 
https://www.sciencedirect.com/science/article/pii/S0261517705000154. Acesso em: 20 jan. 2017.

PALADINI, E. P. Gestão da qualidade: teoria e prática. 2. ed. São Paulo: Atlas, 2006.

PARASURAMAN, A.; ZEITHAML, V. A.; BERRY, L. L. SERVQUAL: A MutipleItem Scale for Measuring Consumer Perceptions of Service Quality. Journal of Retailing, v. 64, n. 1, p. 12-40, 1988. Disponível em: https://search.proquest.com/openview/7d007e04d78261295e5524f15bef6837/1?cbl=41 988\&pq-origsite $=$ gscholar. Acesso em: 14 jan. 2017.

PETROCCHI, M. Hotelaria. Planejamento e Gestão. São Paulo: Futura, 2002.

SILVA, M. M. P. Quem tem boca vai à net. Como a recomendação online transformou o setor de hotelaria e o caso Braga POP Hostel. 2014. 265 f. Dissertação (Mestrado em Ciências da Comunicação: Área de Especialização em Publicidade e Relações Públicas) - Universidade do Minho, Braga, 2014. Disponível em: http://repositorium.sdum.uminho.pt/handle/1822/30451. Acesso em: 1 mar. 2016.

THOMAZI, M. R.; BAPTISTA, M. L. C. Trama de ações investigativas participantes para a pesquisa de turismo em hostel. Anais do Seminário da ANPTUR, 2016. Disponível em: https://www.anptur.org.br/anais/anais/files/13/475.pdf. Acesso em: 26 dez. 2018.

UNESCO. Cidade histórica de Ouro Preto. Disponível em: http://www.unesco.org/new/pt/brasilia/culture/world-heritage/list-of-world-heritage-inbrazil/historic-town-of-ouro-preto/\#c1464984. Acesso em: 1 mar. 2016.

ZEITHAML, V. A.; BITNER, M. J.; GREMLER, D. D. Marketing de serviços: a empresa com foco no cliente. 6. ed. Porto Alegre: AMGH, 2014. 